Open Access

\title{
Assessing seasonality of travel distance to harm reduction service providers among persons who inject drugs
}

\author{
Sean T. Allen ${ }^{1 *}$, Monica S. Ruiz ${ }^{1}$, Amira Roess ${ }^{1}$ and Jeff Jones ${ }^{2}$
}

\begin{abstract}
Background: Prior research has examined access to syringe exchange program (SEP) services among persons who inject drugs (PWID), but no research has been conducted to evaluate variations in SEP access based on season. This is an important gap in the literature given that seasonal weather patterns and inclement weather may affect SEP service utilization. The purpose of this research is to examine differences in access to SEPs by season among PWID in the District of Columbia (DC).

Findings: A geometric point distance estimation technique was applied to records from a DC SEP that operated from 1996 to 2011. We calculated the walking distance (via sidewalks) from the centroid point of zip code of home residence to the exchange site where PWID presented for services. Analysis of variance (ANOVA) was used to examine differences in walking distance measures by season. Differences in mean walking distance measures were statistically significant between winter and spring with PWID traveling approximately 2.88 and 2.77 miles, respectively, to access the SEP during these seasons.

Conclusions: The results of this study suggest that seasonal differences in SEP accessibility may exist between winter and spring. PWID may benefit from harm reduction providers adapting their SEP operations to provide a greater diversity of exchange locations during seasons in which inclement weather may negatively influence engagement with SEPs. Increasing the number of exchange locations based on season may help resolve unmet needs among injectors.
\end{abstract}

\section{Background}

Syringe exchange programs (SEPs) are cost-effective, decrease the incidence of HIV among persons who inject drugs (PWID), and have not been shown to increase drug use, crime, or presence of discarded syringes in neighborhoods [1-5]. SEPs may also provide referrals to other services (e.g., housing, drug treatment, etc.) that may facilitate substance use cessation. The efficacy of SEPs is partially dependent on their accessibility. A study conducted in Baltimore, MD, found that injectors who resided in the same zip code as that of where they exchanged syringes were more likely to engage multiple times with the SEP than their counterparts who resided

\footnotetext{
* Correspondence: seanallen@gwu.edu

'Department of Prevention and Community Health, Milken Institute School of Public Health at The George Washington University, 950 New Hampshire Ave, Suite 300, Washington, DC 20052, USA

Full list of author information is available at the end of the article
}

in a different zip code than where they accessed services [6]. Research has also shown that PWID who reside in close proximity to SEPs are more likely to access services consistently and are less likely to share injection equipment $[7,8]$.

Research conducted among the Philadelphia PWID population examined the spatial relationships between areas of relevance to injectors (e.g., where substances are purchased/used and home residence) [9]. This study found that the distance between injectors' home residence and SEP exchange site was approximately 2.5 miles. Another study conducted among the District of Columbia (DC) PWID population found that injectors traveled approximately 2.75 miles to access services [10].

Notably, no study has examined if differences in SEP access exist among PWID populations based on seasonality. This is an important gap in the literature given that many PWID walk to engage with SEPs [10] and that 
they may be forced to resolve their need for SEP services in the contexts of extreme seasonal weather patterns that create transportation and SEP access barriers. The purpose of this research is to extend our knowledge of SEP access via two primary aims: (1) to quantify the approximate distance between home residence and SEP exchange site by season and (2) to examine seasonal differences in SEP access among DC injectors. We hypothesized that seasonal differences would exist with persons traveling shorter distances to access the SEP in winter.

\section{Findings Methods}

Exchange records from a SEP that operated in DC from 1996 to 2011 were used to calculate the mean walking distance (via sidewalks) PWID traveled to access harm reduction services by season. At the time of registration, each client was asked a series of questions that ascertained their HIV status, zip code of home residence, injection practices, and other sociodemographic information. The dataset also included a record for each exchange event, including the location of where it took place. Because the purpose of this research was to understand SEP access among DC PWID, instances where a person reported a zip code of home residence outside of the District or at a post office box zip code (which may represent a location of convenience rather than a space near the participant's home) were excluded. These exclusion criteria mirrored those used in a similar study of SEP accessibility [10].

Because home residence data were limited to zip code of home residence, a geometric point distance estimation technique was used to calculate the estimated walking distance between the zip code of home residence and exchange location. This technique has been used in other research that examined SEP access among injectors [10]. Briefly, distance measures are calculated using the geometric centroid (i.e., the geometric center) of a given unit of analysis (e.g., a zip code) with the assumption that all data pertaining to the unit of analysis have a common origin at the centroid point $[11,12]$.

All exchange locations were coded using Google Maps [13]. Map data of zip codes in the USA were downloaded from the United States Census Bureau [14] and imported to ArcMap v10.2.1. ArcMap was used to calculate the latitude and longitude coordinates of the centroid point of each zip code. These data points were then merged in Microsoft Excel. A SAS macro was used to quantify the walking distance between the centroid point of each zip code of home residence and exchange location.

Walking distance measures were analyzed by season; however, to achieve a more balanced study design, exchange data were only included in the analyses if there was a complete calendar year of exchanges available. This analytic decision was made because the SEP closed in February 2011 and few exchanges occurred during 2011. A variable was created denoting the approximate meteorological season of each exchange. Following the operationalizations created by the National Oceanic and Atmospheric Association (NOAA), seasons were defined as follows: March, April, and May were coded as spring; June, July, and August were coded as summer; September, October, and November were coded as fall; and December, January, and February were coded as winter [15]. Analysis of variance (ANOVA) was used to test for differences in walking distance measures by season. The George Washington University Institutional Review Board approved this study (IRB\# 111421).

\section{Results}

The dataset included records for 12,094 unique PWID who accessed SEP services from 1996 to 2011. Among these records, $54.3 \%(n=6571)$ had registration data that included zip code of home residence. In order to make the analyses more generalizable, some records were excluded due to small sample sizes and/or missing data; more specifically, persons who identified as transgender $(n=15)$, who had missing gender data $(n=104)$, who identified as a race/ethnicity other than African American/Black or Caucasian/White $(n=84)$, and who had missing race/ethnicity data $(n=30)$ were excluded. These exclusions resulted in a preliminary analytic sample consisting of exchange records from 6638 PWID. Among these persons, $87.8 \%(n=5593)$ reported a DC zip code of home residence; however, only $76.9 \%$ of the records for DC PWID included exchange location data that was viable for distance estimation (i.e., the location(s) of the exchanges could be matched to a specific location). The registration data that were not viable for geocoding stemmed from limitations in how data were recorded at the SEP (i.e., locations that were coded as "Various Sites" or "Unidentified" were not able to be geocoded). Of the remaining 4300 PWID, $84.6 \%$ $(n=3638)$ reported a zip code of home residence in DC that was a geographical zip code (i.e., not a post office box zip code). These 3638 persons and their collective 33,959 total exchange records formed the analytic sample for these analyses. Demographic and substance use profile data of the analytic sample are summarized in Tables 1 and 2 .

The walking distance measures remained relatively constant across all seasons. There were statistically significant differences $(p<0.05)$ in the walking distance measures between spring and winter (2.88 and 2.77 miles, respectively). No other statistically significant differences existed by season. These data are summarized in Tables 3 and 4. 
Table 1 Descriptive statistics of the analytic sample $(n=3,638)$

\begin{tabular}{|c|c|c|}
\hline Variable & & $\%$ of sample \\
\hline \multirow[t]{2}{*}{ Gender } & Male & 74.7 \\
\hline & Female & 25.3 \\
\hline \multirow[t]{2}{*}{ Race } & African American/Black & 96.6 \\
\hline & White & 3.4 \\
\hline \multirow[t]{3}{*}{ Housing status } & Not marginally housed & 27.4 \\
\hline & Marginally housed & 62.4 \\
\hline & Missing housing data & 10.2 \\
\hline \multirow[t]{2}{*}{$\begin{array}{l}\text { Engagement in a drug } \\
\text { treatment program }\end{array}$} & $\begin{array}{l}\text { Never in a drug treatment } \\
\text { program }\end{array}$ & 49.8 \\
\hline & $\begin{array}{l}\text { Previously in a drug } \\
\text { treatment program }\end{array}$ & 50.2 \\
\hline \multirow[t]{4}{*}{ Employment status } & Unemployed & 75.2 \\
\hline & Employed part time & 4.6 \\
\hline & Employed full time & 9.6 \\
\hline & Missing employment data & 10.5 \\
\hline \multirow[t]{5}{*}{ Education level } & Did not graduate high school & 23.5 \\
\hline & $\begin{array}{l}\text { Graduated high school } \\
\text { (no college) }\end{array}$ & 53.5 \\
\hline & $\begin{array}{l}\text { Graduated high school } \\
\text { (some college, no degree) }\end{array}$ & 9.5 \\
\hline & Graduated from college & 3.2 \\
\hline & Missing education data & 10.3 \\
\hline
\end{tabular}

\section{Discussion}

The results of this research extend previous work [10] by providing evidence of seasonal differences in SEP accessibility among DC PWID. The fact that the walking distance measures were significantly different between spring and winter may be explained by seasonal variations in weather. PWID who reside in locations further from the SEP may be less likely to access services during periods of inclement weather. This may explain why the winter access measure was lower than spring (i.e., the winter measure reflected a greater proportion of exchange records from PWID who resided in close proximity to the SEP).

Table 2 Analytic sample substance use measures $(n=3,638)$

\begin{tabular}{llc}
\hline Substance & Reported use & \% of sample \\
\hline Heroin & Did not report use & 12.4 \\
& Reported use & 87.6 \\
Skin popping & Did not report use & 57.5 \\
& Reported use & 42.5 \\
Cocaine & Did not report use & 66.1 \\
& Reported use & 34.0 \\
Speedball & Did not report use & 43.5 \\
& Reported use & 56.5 \\
\hline
\end{tabular}

Table 3 Mean walking distance by season

\begin{tabular}{lcccc}
\hline Season & $\begin{array}{l}\text { Exchanges used in } \\
\text { distance calculations }\end{array}$ & $\begin{array}{c}\text { Mean walking } \\
\text { distance (miles) }\end{array}$ & $\begin{array}{c}\text { Standard } \\
\text { deviation }\end{array}$ & Range \\
\hline Spring & 8,478 & 2.88 & 2.07 & 11.4 \\
Summer & 8,694 & 2.85 & 1.99 & 11.4 \\
Fall & 9,273 & 2.83 & 1.94 & 11.4 \\
Winter & 7,514 & 2.77 & 1.98 & 11.9 \\
\hline
\end{tabular}

The results of this study fill a gap in the public health literature by documenting seasonal differences in one measure of SEP access among PWID. Although the magnitude of the difference in walking distance measures was small between winter and spring, it remains an important finding. These results may be used by SEP stakeholders during discussions pertaining to best practices for SEP service delivery strategies and, more specifically, how to serve the needs of PWID populations during periods of inclement weather (e.g., increasing the number of exchange locations, offering home delivery, etc.). These findings may also be used to guide discussions with policymakers about how the intersection of structural factors (e.g., buffer zone policies that restrict where SEPs may legally operate) that affect SEP access and seasonal impediments to SEP utilization may contribute to a risk environment that is not supportive of the public health of PWID populations.

As noted in previous research [10], one limitation of the geometric point distance estimation method is that it assumes all persons who report a given unit of analysis (e.g., a zip code) reside at a geometric centroid point. Calculations that are more accurate would have been possible with complete home addresses; however, these data were not available. Another limitation of this research is that it is plausible PWID may commute from locations other than their homes (e.g., shooting galleries, locations of drug purchase) to access SEP services and may do so via public or private transportation. These findings may not be reflective of PWID who travel from other locations to access the SEP and/or who do so via public or private transportation. An additional limitation of this research pertains to generalizability. These analyses are reflective of DC PWID and may not necessarily reflect seasonal patterns in SEP access among PWID populations in other locations. This is a notable limitation given that climatic variations based on location may impose

Table 4 ANOVA comparisons of mean walking distance measures by season

\begin{tabular}{llll}
\hline Season & Spring & Summer & Fall \\
\hline Summer & 0.6089 & & \\
Fall & 0.2839 & 0.9508 & \\
Winter & 0.0027 & 0.0938 & 0.2549 \\
\hline
\end{tabular}


differing SEP access impediments (e.g., hurricanes, extreme heat/cold, snowfall, tornadoes, etc.) in different seasons. Lastly, a large number of registrations were missing zip code of home residence data. This is likely due to the SEP's focus on provision of sterile injection equipment rather than uniform and complete data collection.

\section{Conclusion}

In conclusion, these results highlight seasonal differences in SEP accessibility. Inclement weather during winter months may serve as an impediment to service utilization. Harm reduction providers adapting their SEP operations such that services are delivered in more diverse locations during periods of inclement weather when persons may be less inclined to commute to exchange sites may help resolve unmet needs among injectors.

\section{Abbreviations \\ ANOVA: analysis of variance; DC: District of Columbia; PWID: persons who inject drugs; SEPs: syringe exchange programs.}

\section{Competing interests}

The authors declare that they have no competing interests.

\section{Authors' contributions}

SA conceived this analysis and drafted the manuscript with the guidance of MR, AR, and JJ. SA conducted all statistical analyses. MR, AR, and JJ participated in the design and coordination of this research as well as reviewed the findings and assisted in their interpretation. All authors read and approved the final manuscript.

\section{Authors' information}

The authors of this paper represent a team of public health researchers who have extensive experience in the research of health disparities among substance users and other vulnerable populations. SA has experience in conducting geospatial data analyses and mixed-methods research as it pertains to PWID populations. MR has experience in HIV prevention efforts focusing on marginalized populations (such as PWID) and examining how changes in structural factors (such as policies legislating syringe exchange) affect access to harm reduction services among PWID. JJ has experience conducting evaluations of HIV care services and community health assessments of marginalized populations. AR has experience in conducting global health research focused on emerging infectious and zoonotic diseases.

\begin{abstract}
Acknowledgements
This work is part of a larger project-DC POINTE: Policy Impact on the Epidemic - whose main objective is to examine the epidemic impact of policy change as a structural intervention for HIV prevention for PWID in the District of Columbia. This research was supported by a grant to Dr. Monica Ruiz from the National Institute on Drug Abuse (3R01DA031649-03S1). The authors would like to express gratitude to Drs. Karen McDonnell and Jeff Levi for their assistance in this research and sharing with us their understanding of the injector population in DC. We also wish to thank Prevention Works for working tirelessly to combat the HIV/AIDS epidemic in the District and for releasing their data for use in this research. Without the data from Prevention Works, this research would not have been possible. Special thanks to Paola Barahona for assisting with the contextualization of Prevention Works' operations.
\end{abstract}

\section{Author details}

'Department of Prevention and Community Health, Milken Institute School of Public Health at The George Washington University, 950 New Hampshire Ave, Suite 300, Washington, DC 20052, USA. ²Department of Health Policy and Management, Jiann-Ping Hsu College of Public Health at Georgia Southern University, PO Box 8015, Statesboro, GA 30460, USA.
Received: 11 August 2015 Accepted: 5 October 2015

Published online: 12 October 2015

\section{References}

1. Wodak A, Cooney A. Do needle syringe programs reduce HIV infection among injecting drug users: a comprehensive review of the international evidence. Subst Use Misuse. 2006;41:777-813. doi:10.1080/10826080600669579.

2. Hurley SF, Jolley DJ, Kaldor JM. Effectiveness of needle-exchange programmes for prevention of HIV infection. Lancet. 1997;349:1797-800. doi:10.1016/S0140-6736(96)11380-5.

3. Kerr T, Small W, Buchner C, Zhang R, Li K, Montaner J, et al. Syringe sharing and HIV incidence among injection drug users and increased access to sterile syringes. Am J Public Health. 2010;100:1449-53. doi:10.2105/AJPH.2009.178467.

4. Wodak A, Mcleod $L$. The role of harm reduction in controlling HIV among injecting drug users. AIDS. 2008;22:S81-92. doi:10.1097/ 01.aids.0000327439.20914.33.

5. Holtgrave DR, Pinkerton SD, Jones TS, Lurie P, Vlahov D. Cost and costeffectiveness of increasing access to sterile syringes and needles as an HIV prevention intervention in the United States. J Acquir Immune Defic Syndr Hum Retrovirol. 1998;18:S133-8. doi:10.1097/00042560-199802001-00022.

6. Gindi RM, Rucker MG, Serio-chapman CE, Sherman SG. Utilization patterns and correlates of retention among clients of the needle exchange program in Baltimore, Maryland. Drug Alcohol Depend. 2009;103(3):93-8. doi:10.1016/ j.drugalcdep.2008.12.018.

7. Rockwell R, Des jarlais DC, Friedman SR, Perlis TE, Paone D. Geographic proximity, policy and utilization of syringe exchange programmes. AIDS Care. 1999;11:437-42. doi:10.1080/09540129947811.

8. Hutchinson SJ, Taylor A, Goldberg DJ, Gruer L. Factors associated with injecting risk behaviour among serial community-wide samples of injecting drug users in Glasgow 1990-94: implications for control and prevention of blood-borne viruses. Addiction. 2000;95:931-40. doi:10.1046/j.1360-0443.2000.9569319.x.

9. Williams CT, Metzger DS. Race and distance effects on regular syringe exchange program use and injection risks: a geobehavioral analysis. Am J Public Health. 2010;100:1068-74. doi:10.2105/AJPH.2008.158337.

10. Allen ST, Ruiz MS, O'Rourke A. How far will they go? Assessing the travel distance of current and former drug users to access harm reduction services. Harm Reduction J. 2015;12:3. doi:10.1186/s12954-015-0043-4.

11. Berke EM, Shi X. Computing travel time when the exact address is unknown: a comparison of point and polygon ZIP code approximation methods. Int J Health Geogr. 2009;8:23. doi:10.1186/1476-072X-8-23.

12. Birkmeyer JD, Siewers AE, Marth NJ, Goodman DC. Regionalization of high-risk surgery and implications for patient travel times. JAMA. 2003;290:2703-8. doi:10.1001/jama.290.20.2703.

13. Google Maps. [https://www.google.com/maps/]. Accessed 31 Jan 2015.

14. United States Census Bureau: TIGER/Line ${ }^{\oplus}$ Shapefiles and TIGER/Line ${ }^{\oplus}$ Files. [https://www.census.gov/geo/maps-data/data/tiger-line.html ]. Accessed 31 Jan 2015.

15. National Oceanic and Atmospheric Association. [https://www.ncdc.noaa. gov/news/meteorological-versus-astronomical-summer\%E2\%80\%94 what\%E2\%80\%99s-difference ]. Accessed 31 Jan 2015.

\section{Submit your next manuscript to BioMed Central and take full advantage of:}

- Convenient online submission

- Thorough peer review

- No space constraints or color figure charges

- Immediate publication on acceptance

- Inclusion in PubMed, CAS, Scopus and Google Scholar

- Research which is freely available for redistribution 